\title{
Do rainbow trout and Atlantic salmon discriminate kin?
}

\author{
Grant E. Brown \\ Ocean Sciences Centre and Biopsychology Programme, Memorial University of Newfoundland, St. John's, Nfld., \\ Canada AlC $5 S 7$ \\ AND
}

JOSEPH A. BROWN

Ocean Sciences Centre, Memorial University of Newfoundland, St. John's, Nfld., Canada A1C 5S7

Received November 26, 1991

Accepted March 3, 1992

\begin{abstract}
Brown, G. E., and Brown, J. A. 1992. Do rainbow trout and Atlantic salmon discriminate kin? Can. J. Zool. 70: $1636-1640$.

The purpose of this study was to determine if juvenile Atlantic salmon (Salmo salar) and rainbow trout (Oncorhynchus mykiss) can discriminate kin from non-kin, since other salmonid species (coho salmon (Oncorhynchus kisutch) and Arctic charr (Salvelinus alpinus)) have been shown to possess this ability. When tested in water conditioned by conspecifics (kin and non-kin) and heterospecifics in a two-choice tank, both rainbow trout and Atlantic salmon demonstrated a significant preference for kin over non-kin and heterospecifics, indicating that these species possess kin-discrimination abilities. This ability appears to be widespread among salmonid fishes.

Brown, G. E., et Brown, J. A. 1992. Do rainbow trout and Atlantic salmon discriminate kin? Can. J. Zool. 70 : $1636-1640$.

Le but de l'expérience était de déterminer si des Saumons atlantiques (Salmo salar) et des Truites arc-en-ciel (Oncorhynchus mykiss) juvéniles sont capables de distinguer l'eau de poissons apparentés de celle de poissons non apparentés, comme d'autres espèces de salmonidés (le Saumond coho (Oncorhynchus kisutch) et l'Omble arctique (Salvelinus alpinus)) que l'on sait posséder ces propriétés. Les juvéniles des deux espèces ont été placés dans un aquarium offrant un choix entre le l'eau préalablement occupée par des conspécifiques (parents ou non) ou de l'eau préalablement occupée par des poissons hétérospécifiques, et ont montré une préférence significative pour l'eau de poissons apparentés (plutôt que celle de poissons non apparentés ou de poissons hétérospécifiques), ce qui indique que ces espèces sont capables de reconnaître l'eau des poissons qui leur sont apparentés. Cette propriété semble répandue chez les salmonidés.
\end{abstract}

[Traduit par la rédaction]

\section{Introduction}

The ability to discriminate kin (kin recognition) can be inferred when an individual exhibits differential behaviour towards conspecifics based on the degree of relatedness (Hepper 1986; Fletcher 1987; Waldman et al. 1988; Armitage 1989). Kin-discrimination abilities have been demonstrated in species ranging from eusocial insects to humans (e.g., insects (Breed and Bennett 1987; Michener and Smith 1987), amphibians (O'Hara and Blaustein 1982; Blaustein and O'Hara 1986; Jasienski 1988), fish (McKaye and Barlow 1976; Barnett 1977, 1981), nonhuman mammals (Blaustein et al. 1987; Walters 1987), humans (Wells 1987)). In salmonid fishes, studies have demonstrated that juvenile coho salmon (Oncorhynchus kisutch) and Arctic charr (Salvelinus alpinus) are capable of discriminating between kin and non-kin individuals, and prefer kin when given the 'choice' (Quinn and Busack 1985; Quinn and Hara 1986; Olsen 1989). The basis for this discrimination is olfactory cues, although the above authors do not exclude the possibility of the secondary use of other sensory modalities (i.e., vision).

Both rainbow trout and Atlantic salmon share life-history traits with coho salmon and Arctic charr (e.g., Scott and Crossman 1973; Dill 1977; Berg and Northcote 1985), and so we predicted that the two former salmonid species will also discriminate between kin and non-kin. In addition, if rainbow trout and Atlantic salmon do discriminate kin, this would bring the total of representative salmonid fishes that possess this ability to four, suggesting that the phenomenon is relatively widespread among salmonids.

\section{Methods}

\section{Test fish}

Domestic rainbow trout and wild-caught Atlantic salmon broodstock were used to create kin groups. For each species the eggs of one female were fertilized with the milt of one male (two females and two males were used to give two distinct kin groups per species). After water hardening (hardening of the egg by adding water after fertilization), each kin group was divided into two, giving four groups for each species (kin reared together and reared apart for two kin groups), which were placed in separate trays in an incubator system. After yolk absorption, the fry were placed in tanks fed by a partially recirculating water supply with approximately $150 \%$ water replacement per day. The sides of each tank were covered with black plastic to prevent visual contact with conspecifics. Fish were fed ad libitum three times per day with salmon-trout starter feed. Water temperature in the holding tanks and the test tank ranged from 9 to $12.5^{\circ} \mathrm{C}$ over the study period. The density of fry was approximately 200 per 80 -L holding tank. Testing began approximately 3 months posthatching (mean weight $1.55 \pm 0.48$ and $0.81 \pm 0.24 \mathrm{~g}$ and mean length $2.41 \pm 0.32$ and $3.1 \pm 0.30 \mathrm{~cm}$ for trout and salmon, respectively).

\section{Test tank}

The test apparatus consisted of an opaque acrylic tank, similar to that employed by Quinn and Busack (1985). The tank measured $110 \mathrm{~cm}$ long $\times 35 \mathrm{~cm}$ wide $\times 35 \mathrm{~cm}$ high, with a centre dividing wall of opaque acrylic running lengthwise down the tank. A removable opaque barrier was placed $25 \mathrm{~cm}$ from the downstream end of the tank (at the end of the centre dividing wall) creating a startacclimation area. Outflows at the downstream end of each channel maintained the water level at approximately $7 \mathrm{~cm}$. Four $25-\mathrm{L}$ buckets 
TABLE 1. Initial and final choices made by Atlantic salmon and rainbow trout

\begin{tabular}{|c|c|c|c|c|c|c|c|}
\hline \multirow[b]{2}{*}{ Trial configuration } & \multicolumn{3}{|c|}{ Initial choice } & \multicolumn{4}{|c|}{ Final choice } \\
\hline & $\mathrm{C}$ & IC & $p$ & $\mathrm{C}$ & IC & $\mathrm{NC}$ & $p$ \\
\hline \multicolumn{8}{|l|}{ Atlantic salmon } \\
\hline Kin vs. blank & 11 & 9 & 0.412 & 11 & 5 & 4 & 0.105 \\
\hline Non-kin vs. blank & 9 & 11 & 0.412 & 16 & 2 & 2 & 0.001 \\
\hline Kin vs. non-kin & 22 & 18 & 0.356 & 24 & 9 & 7 & 0.007 \\
\hline Non-kin vs. trout & 11 & 9 & 0.412 & 15 & 2 & 3 & 0.001 \\
\hline \multicolumn{8}{|l|}{ Rainbow trout } \\
\hline Kin vs. blank & 11 & 9 & 0.412 & 17 & 1 & 2 & 0.001 \\
\hline Non-kin vs. blank & 8 & 12 & 0.252 & 16 & 1 & 3 & 0.001 \\
\hline Kin vs. non-kin & 18 & 22 & 0.356 & 29 & 6 & 5 & 0.001 \\
\hline Non-kin vs. salmon & 10 & 10 & 0.588 & 16 & 2 & 2 & 0.004 \\
\hline
\end{tabular}

Note: Binomial test; C, correct choice; IC, incorrect choice; NC, no choice.

were used to provide flow through the tank. Two buckets were filled continuously with water from the ambient fresh water supply, which was fed into the tank at approximately $2.5 \mathrm{~L} \cdot \mathrm{min}^{-1}$. Cue water, taken directly from the corresponding holding tank(s), depending upon the trail configuration, was supplied from the remaining two buckets to the tank at approximately $1 \mathrm{~L} \cdot \mathrm{min}^{-1}$. The combined flow of the cue and ambient waters was sufficient to generate a mean current of approximately $6-8 \mathrm{~cm} \cdot \mathrm{s}^{-1}$.

\section{Experimental protocol}

Fish were tested in one of four trial configurations: $(i)$ kin vs. blank water sample (ambient fresh pond water), (ii) non-kin vs. blank water sample, (iii) kin vs. non-kin, and (iv) non-kin vs. heterospecific. For either species, 20 fish were tested individually per trial configuration, and each fish was tested only once. In the case of the kin vs. non-kin trials, siblings reared together and separately were tested (20 of each, i.e., $n=40$ for kin vs. non-kin trials).

A single fish was placed in the start area of the test tank and allowed a 5-min acclimation period, then the flow was started and the fish was given an additional $10 \mathrm{~min}$ to acclimate. At this time the removable opaque barrier was lifted and the trial began. Test trials lasted $10 \mathrm{~min}$, and two behavioural measures were recorded: (i) initial and final choice (or no choice), and (ii) percent time spent in choice alleys or the no-choice area. The fish was considered to have made a 'correct' choice when it responded to the water conditioned by kin (or non-kin in the case of the non-kin vs. blank and non-kin vs. heterospecific trials), and to have made an 'incorrect' choice when it was in the other choice alley. In addition, the number of times the fish moved from one area of the tank to another ('change') was recorded. The fish was recorded as making a choice when it was oriented towards the flow and at least one-half of its body had crossed the position of the removable barrier. The initial choice was the first crossing into either alley; the position of the fish at the completion of the trial was recorded as the final choice. Time spent in the correct choice alley, incorrect choice alley, and start area (no choice) was recorded, and the proportions were calculated by dividing by total time. The location of water was reversed each trial, to avoid location bias. The tank and buckets were drained and rinsed with salt water and then with ambient fresh water between trials to ensure that chemosensory cues did not remain from previous trails.

Initial and final choices were analyzed using a binomial test for deviations from chance distribution (Siegal 1956). The proportions of time were analyzed using Friedman's analysis of variance and Wilcoxon's signed ranks tests (Siegal 1956; Sokal and Rohlf 1981) for individual comparisons, and the number of changes was analyzed using a two-tailed Student's $t$-test (Sokal and Rohlf 1981).

\section{Results}

When the opaque barrier was removed, both salmon and trout swam about the tank. Movements typically ceased after 3-5 min, at which time the fish would hold position near the upstream end (i.e., close to the source of the cue) of a choice alley. Salmon were generally more active, making significantly more changes than trout (mean changes $15.6 \pm 2.96$ vs. $11.9 \pm 1.35$ for salmon and trout, respectively; Student's $t=$ $4.381, p<0.0003)$. Neither species showed significant differences in the initial choice (i.e., made as many correct as incorrect choices) over any of the four trial configurations (Table 1). In all trials both Atlantic salmon and rainbow trout demonstrated significant differences in the final choice, choosing the correct alley over the incorrect alley (Table 1).

For the kin vs. non-kin configuration, trials run with siblings reared together or apart were compared using Wilcoxon's signed ranks test. No significant differences were found between kin reared together and those reared apart (Atlantic salmon: $Z=1.12, p=0.26$; rainbow trout: $Z=0.07, p=$ $0.96)$ and data were pooled for further analysis. Both rainbow trout and Atlantic salmon spent a significantly greater proportion of time in the correct choice alley (e.g., in the kin alley for the kin vs. non-kin trial configuration) in each of the four trial configurations. This indicates a preference for kin over blank water, non-kin over blank water, non-kin over heterospecifics, and kin over non-kin in each of the trial configurations (Table 2, Figs. 1 and 2).

\section{Discussion}

These data demonstrate that both specifics are capable of discriminating kin from non-kin conspecifics on the basis of water-borne chemosensory cues. Both Atlantic salmon and rainbow trout spent a significantly greater proportion of time in water conditioned by kin than in water conditioned by nonkin when given the choice, and were observed to have made significantly more correct choices at the completion of the 10-min observations.

It has been argued that the adaptive significance of the ability of salmonids to discriminate kin is primarily associated with schooling behaviour (Quinn and Busack 1985; Olsen 1989), though this hypothesis has not been experimentally examined. It is argued that a variety of benefits may accrue from schooling with kin rather than with non-kin (e.g., decreased risk of predation, increased foraging efficiency, cooperation within a school (Waldman 1982; Quinn and Busack 1985; Olsen 1989).

Rainbow trout and Atlantic salmon are highly territorial at the juvenile, stream-dwelling stage, as are coho salmon and, to a lesser extent, Arctic charr. Both rainbow trout and Atlantic salmon begin to actively defend feeding territories shortly upon emerging from the redd (the nest excavated by the female in the gravel substrate; Burner 1951; Dill 1977; Gibson 1978), and remain almost exclusively territorial until they leave the stream as smolts (Scott and Scott 1988). Thus, the suggestion concerning adaptive significance put forward for coho salmon (Quinn and Busack 1985) and Arctic charr (Olsen 1989) may not be sufficient to explain the kin-discrimination ability of either rainbow trout or Atlantic salmon. Other explanations of adaptive significance associated with kin discrimination should be postulated, particularly those associated with ter- 

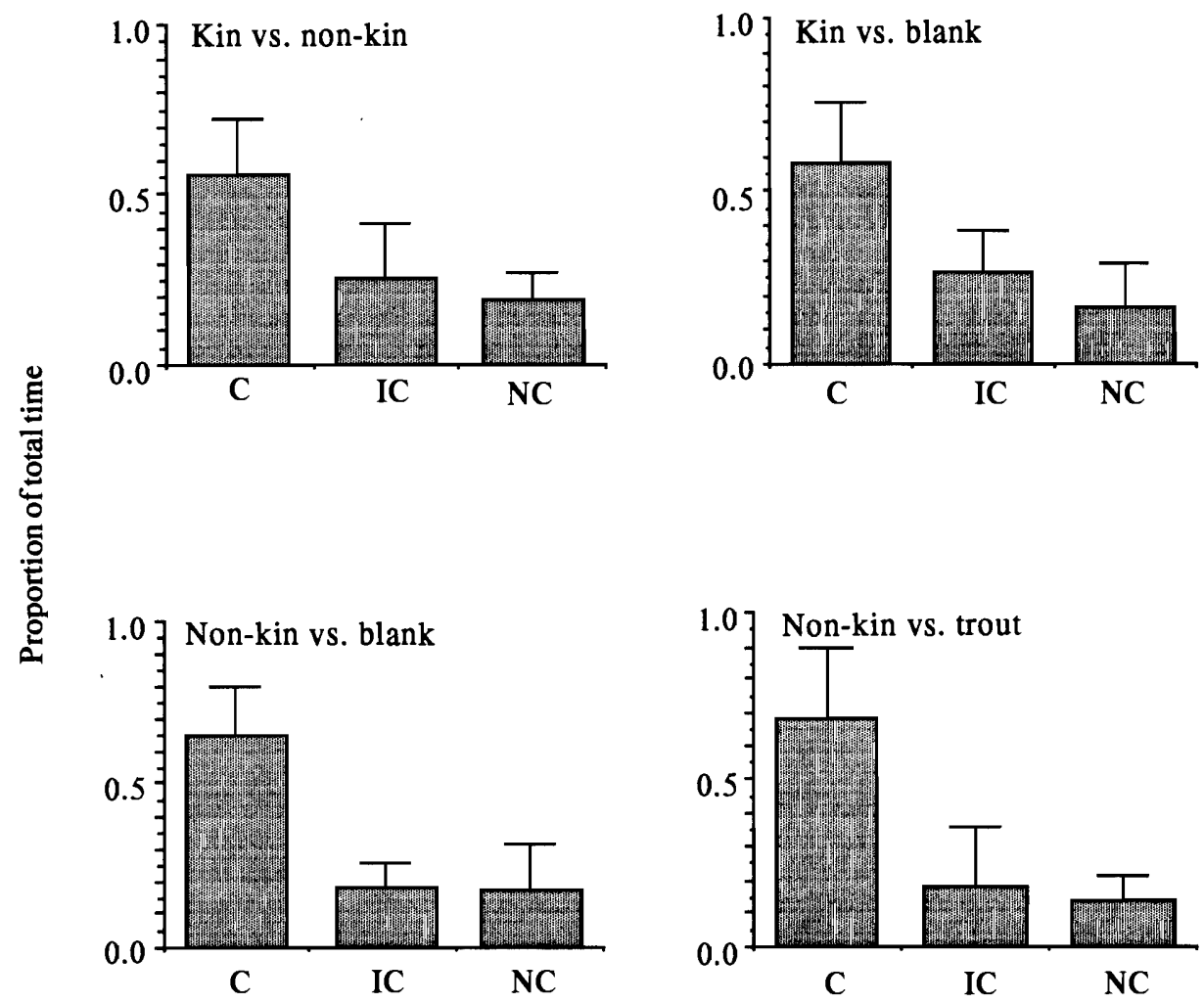

Fig. 1. Proportion of time spent in the choice alleys and (or) the no-choice area of the test tank for Atlantic salmon in the various trial configurations. C, correct choice; IC, incorrect choice; NC, no choice. Vertical bars show 1 standard deviation; $n=20$, except for kin vs. non-kin trials, where $n=40$. See text for details.

TABLE 2. Statistical comparisons of time spent by Atlantic salmon and rainbow trout in each section of the test tank, including overall (Friedman's analysis of variance $\left(\chi^{2}\right)$ ) and individual (Wilcoxon's signed ranks $(Z)$ ) comparisons and probabilities for each of the four trial configurations

\begin{tabular}{lcccr}
\hline \hline & $\begin{array}{c}\text { Overall } \\
\left(\chi^{2}\right)\end{array}$ & $\begin{array}{c}\text { Correct vs. } \\
\text { incorrect } \\
(Z)\end{array}$ & $\begin{array}{c}\text { Correct vs. } \\
\text { no choice } \\
(Z)\end{array}$ & $\begin{array}{c}\text { Incorrect vs. } \\
\text { no choice } \\
(Z)\end{array}$ \\
\hline Trial configuration & & & & \\
$\begin{array}{l}\text { Atlantic salmon } \\
\text { Kin vs. blank }\end{array}$ & $18.1^{*}$ & $-3.33^{*}$ & $-3.69^{*}$ & $-2.07 *$ \\
Non-kin vs. blank & $25.2^{*}$ & $-3.85^{*}$ & $-3.73^{*}$ & $-0.37 \mathrm{~ns}$ \\
Kin vs. non-kin & $21.7^{*}$ & $-3.58^{*}$ & $-3.92^{*}$ & $-0.37 \mathrm{~ns}$ \\
Non-kin vs. trout & $39.6^{*}$ & $-4.31^{*}$ & $-5.40^{*}$ & $-1.56 \mathrm{~ns}$ \\
Rainbow trout & & & & $1.15 \mathrm{~ns}$ \\
Kin vs. blank & $15.2^{*}$ & $-3.78^{*}$ & $-2.94 *$ & $0.53 \mathrm{~ns}$ \\
Non-kin vs. blank & $27.1^{*}$ & $-3.92^{*}$ & $-3.88^{*}$ & $-0.75 \mathrm{~ns}$ \\
Kin vs. non-kin & $24.4^{*}$ & $-3.73^{*}$ & $-3.92^{*}$ & $-1.44 \mathrm{~ns}$ \\
Non-kin vs. salmon & $40.2^{*}$ & $-4.77^{*}$ & $-5.29 *$ & \\
\hline
\end{tabular}

NOTE: ${ }^{*}, p \leq 0.05 ;$ ns, not significant at $p>0.05$

ritorial behaviours. Preferentially defending territories near kin rather than non-kin may serve to increase an individual's direct and indirect (inclusive fitness; Wilson 1975) benefits. This may be achieved through a reduction in the frequency of territorial defence behaviours exhibited in the presence of kin (Brown and Brown 1992).

Grafen (1990) suggests that the phenomenon commonly referred to as kin discrimination (recognition) is merely an artefact of conspecific recognition. He argues that since kin are typically the first conspecifics encountered, it is an individ- ual's familiarity with kin that biases conspecific recognition of kin. This will appear as a behavioural preference for related conspecifics. There are two components to Grafen's model: simple familiarity and a genetic component of recognition cues. A partial test of Grafen's hypothesis would be to eliminate the effects of familiarity. While we observed no differences between kin reared together and apart, we cannot refute Grafen's arguments concerning familiarity, since a partially recirculating water supply was employed for this study. To control for the effects of familiarity, and, hence, to test 

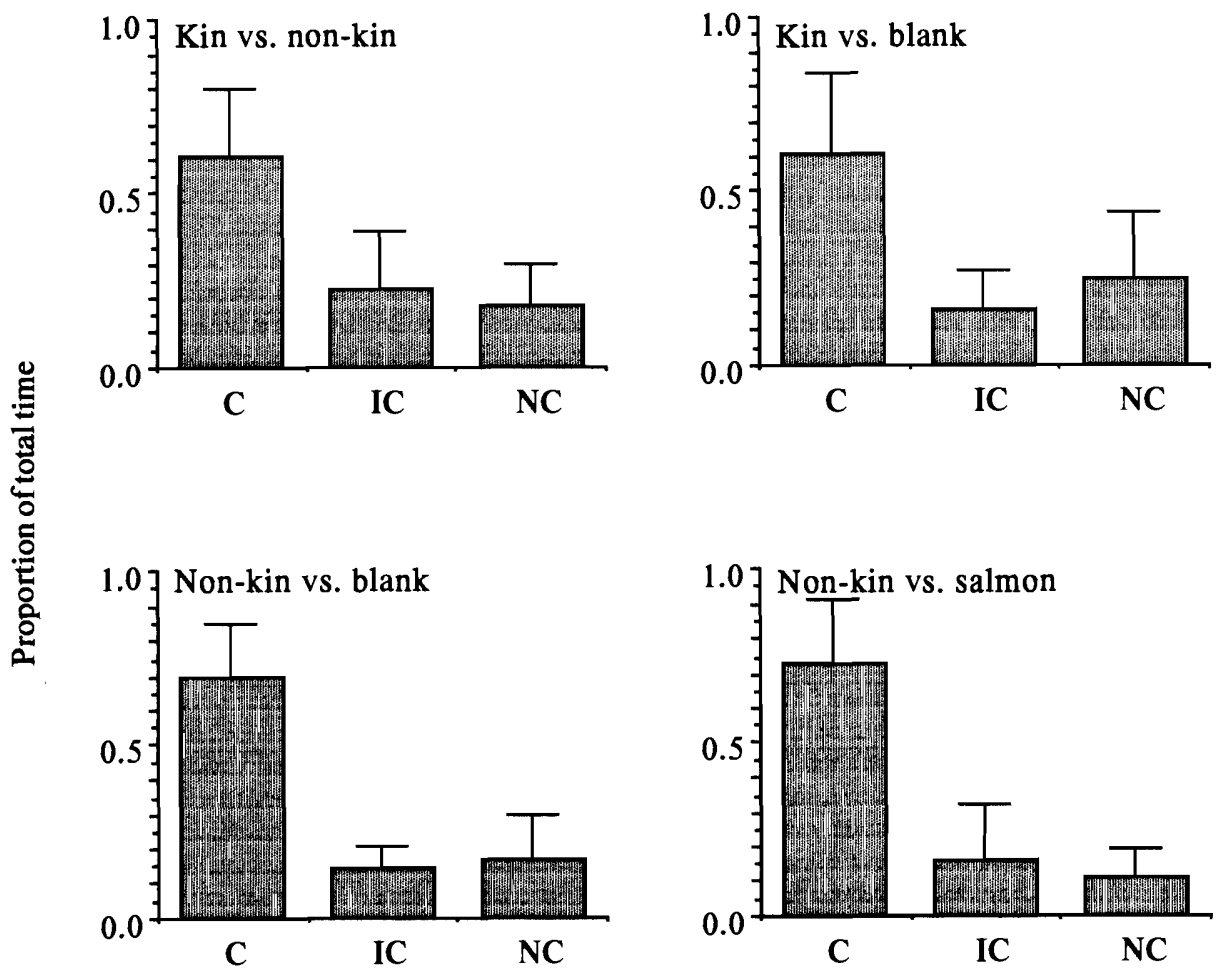

FIG. 2. Proportion of time spent in the choice alleys and (or) the no-choice area of the test tank for rainbow trout in the various trial configurations. C, correct choice; IC, incorrect choice; NC, no choice. Vertical bars show 1 standard deviation; $n=20$, except for kin vs. non-kin trials, where $n=40$. See text for details.

Grafen's hypothesis, eggs and fry would have to be reared in complete isolation from the time of fertilization until testing. While this would not address the genetic component of Grafen's hypothesis, it would allow us to eliminate familiarity as the mechanism of kin discrimination in these salmonids.

The two behavioural measures employed during this study are common to tests of kin discrimination in a wide variety of species (e.g., Quinn and Busack 1985; Quinn and Hara 1986; Blaustein and O'Hara 1986; Olsen 1989). The data suggest, though, that the proportion of time spent in each stream channel is a more reliable dependant variable. Both measures suggest the existence of kin discrimination in these fishes, but the initial - final choice measure may be open to artefacts (type II errors). If a fish were to make several changes it is possible that upon completion of the 10-min observation period, it had just moved from the correct to the incorrect choice alley, so an incorrect response was recorded. It is possible that the fish had spent most of the time in the correct choice alley. This was likely the case in the salmon kin vs. blank trial configuration, where no significant difference was observed between correct and incorrect final choices. By relying solely upon the initial final choice measure, we may have obscured the results (increased type II error) and failed to conclude that both rainbow trout and Atlantic salmon are capable of kin discrimination.

In summary, it appears that both rainbow trout and Atlantic salmon are capable of discriminating conspecifics on the basis of water-borne chemosensory cues. The results of this study bring to four the total of salmonid species that have been shown to possess this ability, suggesting that this phenomenon may be widespread among salmonids.

\section{Acknowledgements}

The authors thank Ed Downton and Memorial University of Newfoundland Tech Services for their assistance in constructing the test apparatus; Dr. Willie Davidson, John Goodier, and Colin McGowan for the salmon broodstock; Jim Nagler for the trout broodstock; and Drs. Thomas Quinn and John Gibson, and Kelly Kambeitz, Dave Rosen, and P. J. Williams for comments on earlier versions of the manuscript. Financial support was provided by an operating grant from the Natural Sciences and Engineering Research Council of Canada to J.A.B. This is Ocean Sciences Centre Contribution No. 111.

Armitage, K. B. 1989. The function of kin discrimination. Ethol. Ecol. Evol. 1: 111-121.

Barnett, C. 1977. Chemical recognition of the mother by the young of the cichlid fish Cichlasoma citrinellum. J. Chem. Ecol. 3: $461-$ 466.

Barnett, C. 1981. The role of urine in parent-offspring communication in a cichlid fish. Z. Tierpsychol. 55: 173-182.

Berg, L., and Northcote, T. G. 1985. Changes in territorial, gillflaring, and feeding behaviour in juvenile coho salmon (Oncorhynchus kisutch) following short term pulses of suspended sediment. Can. J. Fish. Aquat. Sci. 42: 1410-1417.

Blaustein, A. R., and O'Hara, R. K. 1986. Kin recognition in tadpoles. Sci. Am. 254: 108-116.

Blaustein, A. R., Bekoff, M., and Daniels, T. J. 1987. Kin recognition in vertebrates (excluding primates): empirical evidence. In Kin recognition in animals. Edited by D. J. C. Fletcher and C. D. Michener. John Wiley and Sons, Toronto. pp. 287-332.

Breed, M. D., and Bennett, B. 1987. Kin recognition in highly eusocial insects. In Kin recognition in animals. Edited by D. J. C. Fletcher and C. D. Michener. John Wiley and Sons, Toronto. pp. $243-286$. 
Brown, G. E., and Brown, J. A. 1992. Social dynamics in salmonid fishes: Do kin make better neighbours? Anim. Behav. In press.

Burner, A. J. 1951. Characteristics of spawning nests of Columbia River salmon. U.S. Fish Wildl. Serv. Fish. bull. 61: 97-110.

Dill, P. 1977. Development of behaviour in alevins of Atlantic salmon, Salmo salar, and rainbow trout $S$. gairdneri. Anim. Behav. 25: $116-121$.

Fletcher, D. J. C. 1987. The behavioural analysis of kin recognition: perspectives on methodology and interpretation. In Kin recognition in animals. Edited by D. J. C. Fletcher and C. D. Michener. John Wiley and Sons, Toronto. pp. 19-54.

Gibson, R. J. 1978. The behaviour of juvenile Atlantic salmon (Salmo salar) and brook trout (Salvelinus fontinalis) with regard to temperature and water velocity. Trans. Am. Fish. Soc. 103: 707712.

Grafen, A. 1990. Do animals really recognize kin? Anim. Behav. 39: $42-54$

Hepper, P. G. 1986. Kin recognition: functions and mechanisms, a review. Biol. Rev. Camb. Philos. Soc. 61: 64-93.

Jasienski, M. 1988. Kinship ecology of competition: size hierarchies in kin and non-kin laboratory cohorts of tadpoles. Oecologia, 77: $407-413$.

McKaye, K., and Barlow, G. W. 1976. Chemical recognition of young by the Midas cichlid, Cichlasoma citrinellum. Copeia, 1976: 276-282.

Michener, C. D., and Smith, B. H. 1987. Kin recognition in primitively eusocial insects. In Kin recognition in animals. Edited by D. J. C. Fletcher and C. D. Michener. John Wiley and Sons, Toronto. pp. 209-242.

O'Hara, R. K., and Blaustein, A. R. 1982. Kin preference behaviour in Bufo boreas tadpoles. Behav. Ecol. Sociobiol. 11: 43-49.
Olsen, K. H. 1989. Sibling recognition in juvenile Arctic charr, Salvelinus alpinus (L.). J. Fish Biol. 34: 571-581.

Quinn, T. P., and Busack, C. A. 1985. Chemosensory recognition of siblings in juvenile coho salmon, (Oncorhynchus kisutch). Anim. Behav. 3: 51-56.

Quinn, T. P., and Hara, T. J. 1986. Sibling recognition and olfactory sensitivity in juvenile coho salmon (Oncorhynchus kisutch). Can. J. Zool. 64: $921-925$.

Scott, W. B., and Crossman, E. J. 1973. Freshwater fishes of Canada. Can. Bull. Fish. Aquat. Sci. No. 184.

Scott, W. B., and Scott, M. G. 1988. Atlantic fishes of Canada. Can. Bull. Fish. Aquat. Sci. No. 218.

Siegal, S. 1956. Nonparametric statistics for the behavioural sciences. McGraw-Hill, New York.

Sokal, R. J., and Rohlf, F. J. 1981. Biometry. W. H. Freeman, San Francisco.

Waldman, B. 1982. Sibling associations among schooling toad tadpoles: field evidence and implications. Anim. Behav. 30: 700713.

Waldman, B., Frumhoff, P. C., and Sherman, P. W. 1988. Problems of kin recognition. Trends Ecol. Evol. 3: 8-13.

Walters, J. R. 1987. Kin recognition in non-human primates. In Kin recognition in animals. Edited by D. J. C. Fletcher and C. D. Michener. John Wiley and Sons, Toronto. pp. 359-394.

Wells, P. A. 1987. Kin recognition in humans. In Kin recognition in animals. Edited by D. J. C. Fletcher and C. D. Michener. John Wiley and Sons, Toronto. pp. 395-416.

Wilson, E. O. 1975. Sociobiology. Belknap Press of Harvard University Press, Cambridge.

\title{
Influence of storms and maternal size on mother - pup separations and fostering in the harbor seal, Phoca vitulina
}

\author{
DARYL J. BONESS \\ Department of Zoological Research, National Zoological Park, Smithsonian Institution, Washington, DC 20008, U.S.A. \\ DON BOWEN \\ Marine Fish Division, Bedford Institute of Oceanography, Dartmouth, N.S., Canada B2Y $4 A 2$ \\ SARA J. IVERSON ${ }^{1}$ \\ Department of Physiology and Biophysics, Georgetown University Medical Center, Washington, DC 20009, U.S.A. \\ AND \\ Olav T. OfTEDal \\ Department of Zoological Research, National Zoological Park, Smithsonian Institution, Washington, DC 20008, U.S.A. \\ Received January 3, 1991 \\ Accepted February 27, 1992
}

Boness, D. J., Bowen, D., Iverson, S. J., and Oftedal, O. T. 1992. Influence of storms and maternal size on mother-pup separations and fostering in the harbor seal, Phoca vitulina. Can. J. Zool. 70: 1640-1644.

Fostering behavior has been documented in a large number of mammals and birds, but its frequency of occurrence and proximate causes are poorly understood in most species. Ten percent of a sample of 76 paint-marked female harbor seals (Phoca vitulina) fostered pups for some portion of the lactation period. Fostering appears to be associated with females having lost their own pup. In a subsample of 30 pairs that were followed closely, 3 of 16 females that lost their pups fostered, but none of 14 females that maintained continuous association with their pups throughout lactation did so. Smaller, and presumably younger, females were significantly more likely to become separated from their pups than were larger, and presumably older, females ( 73 vs. $33 \%$ ). A high proportion (68\%) of 35 separations observed occurred during the same day as, or within 1 day following, a storm. In 7 of 8 instances where we relocated pups after they were separated from their mothers during a storm, we found them in the direction of the surface current, $4.9 \mathrm{~km}$ from their previous location, on average. These data suggest that storms were the primary cause of separation of harbor seal mothers from their pups, and that younger mothers may be more likely to become separated from their pups. As fostering only occurs after a mother has lost her pup, we suggest that fostering, too, may be more likely among younger females. 